\title{
Patient-reported outcomes of multifocal and accommodating intraocular lenses: analysis of II 7 patients 2-10 years after surgery
}

This article was published in the following Dove Press journal:

Clinical Ophthalmology

\section{John A Hovanesian ${ }^{1,2}$}

'Harvard Eye Associates, Laguna Hills, CA, USA; ${ }^{2}$ Clinical Faculty, UCLA Jules Stein Eye Institute, Los Angeles, CA, USA
Correspondence: John A Hovanesian Harvard Eye Associates, 2440I Calle De La Louisa, Laguna Hills, CA 92653, USA $\mathrm{Tel}+$ I 949 95। 2020

$\mathrm{Fax}+19499519244$

Email johnhova@gmail.com
Purpose: The purpose of this study was to determine the satisfaction levels of patients at least 2 years after cataract surgery implantation with bilateral accommodating or bilateral multifocal intraocular lenses (IOLs) and to determine the relative rate of spectacle independence and adverse symptoms in that same time frame.

Design: Patient questionnaire administered in a single-center private practice at least 2 years after cataract surgery with presbyopia-correcting IOL implantation.

Methods: Patients who had undergone uncomplicated cataract surgery with an accommodating or multifocal IOL implant were eligible for inclusion. Patients with visually significant nonIOL-related postoperative morbidity were excluded. Patients with astigmatism or residual refractive error were not excluded. The main outcome measure was patient satisfaction at least 2 years after IOL implantation.

Results: Sixty-eight patients who received accommodating lenses and 49 patients who received multifocal lenses completed the questionnaire. The mean age of all patients was 75.7 years at the time of survey; the mean number of years since cataract surgery was 5.4 years. Overall, there were no significant differences between the two groups or within each group between the different lenses used. About $90 \%$ of patients in each group were "very satisfied" or "somewhat satisfied" with their vision at least 2 years after the initial surgery. Conversely, only one in eleven patients found his vision to be worse than expected.

Conclusions: The majority of patients who received either accommodating or multifocal IOLs remain satisfied with their lens of choice more than 5 years after the original surgery. Glare and halos remain more noticeable in patients who received multifocal lenses.

Keywords: intraocular lenses, accommodating IOLs, multifocal IOLs, patient-reported satisfaction, presbyopia, crystalens, ReSTOR, Tecnis, satisfaction, glasses

\section{Introduction}

Presbyopia-correcting intraocular lenses (IOLs) have been available in Europe and the United States for more than a decade, offering the prospect of correcting both cataract and refractive error. Multiple studies have demonstrated a clear relationship between refractive accuracy and patient-reported satisfaction with both accommodating and multifocal lenses; one cannot be achieved without the other. ${ }^{1-8}$ However, most patient-reported outcomes and satisfaction studies have been conducted with $<1$ year of follow-up. ${ }^{2-4,8}$

The patient-perceived value of any refractive solution is borne out over the long term. There are a multitude of reasons why initial patient satisfaction may wane over the years, including a return to spectacle dependence for near tasks, onset of 
maculopathy in an eye that was healthy at the time of surgery, or onset/progression of dry eye that can affect vision and daily functioning. There may also be reasons patients cite a diminished satisfaction level that are not related to the surgery. One potential reason for patient-reported dissatisfaction over the long term is a significant change in the efficacy of the lens itself.

The purpose of this study, therefore, was to determine if there is a clear difference in the long-term patient satisfaction of these types of lenses among patients who underwent presbyopia-correcting surgery and had healthy eyes at the time of the procedure. To the author's knowledge, this is the only study to evaluate patient-reported outcomes and satisfaction an average of 5 years postoperatively. The primary outcome was the level of patient-reported satisfaction without regard to refractive outcomes. The secondary outcome was the length of time a patient reported dissatisfaction (if any) with the implant.

\section{Methods}

This was a prospective analysis of long-term patient-reported outcomes and satisfaction of post-cataract surgery with an accommodating or multifocal bilateral IOL implantation. All eyes were implanted with the Crystalens (Bausch + Lomb, Bedminster, NJ, USA), the AcrySof IQ ReSTOR (Alcon, Ft Worth, TX, USA), or the Tecnis Multifocal 4.0D (AMO, Abbott Park, IL, USA) IOL, with the surgeon using the most recent iteration/model number available at the time of cataract surgery. Patients who had undergone uncomplicated cataract surgery at least 2 years prior were identified through a database search and considered for enrollment in the patient-reported outcomes survey. In an attempt to identify 50 patients who could be enrolled in each group (multifocal and accommodating lenses), we searched data on all cataract surgeries performed from June 2005 to July 2013.

At the time of cataract surgery, all patients had a potential visual acuity (VA) of 20/25 as ascertained by the cataract surgeon, with a refractive goal in the nondominant eye of $-0.75 \mathrm{D}$ for patients receiving the Crystalens and a refractive goal of plano/plano in the multifocal IOL patients. ("Potential VA" was defined as predicted best corrected VA, with or without spectacles.) Exclusion criterion was any patient who had developed visually significant non-IOLrelated morbidities during the postoperative period. Patients who had undergone postoperative YAG laser capsulotomy or laser refractive enhancement procedures were not excluded from the study. For the purposes of this analysis, an examiner masked to the type of implant examined a table from a database query showing the recent findings (not including IOL type) and diagnoses of all patients who responded to the questionnaire. (See Figure S1 for the questionnaire.) If, at the time of the survey, the patient had severe dry eye, maculopathy, posterior capsule opacification, or previous refractive surgery, the patient was excluded from analysis. Neither astigmatism nor residual refractive error were exclusion factors, as the author believes either of those conditions may affect patient-reported satisfaction.

The survey was administered in a single-center private practice setting by a technician masked to the type of IOL implant. Initially 224 patients were identified who could participate in the study; of those, 117 patients met both the inclusion/exclusion criteria and responded to the questionnaire and, therefore, had analyzable data. Of those, 68 patients received accommodating IOLs and 49 patients received multifocal IOLs.

Aspire IRB (Santee, CA, USA) approved the study protocol, and all participating patients provided a written informed consent, consistent with the Declaration of Helsinki.

\section{Results Demographics}

Overall, the mean age of all patients was 75.7 years at the time of the survey (range, 56-93 years), and the mean number of years since cataract surgery was 5.4 years (range, $2-10$ years). Those who received an accommodating lens (group $1 ; n=68$ ) had a mean age of 75.8 years (range, 56-91 years) at the time of the survey, and the mean number of years since cataract surgery was 6.1 years (range, 2-10 years). Those who received a multifocal lens (group 2; $n=49$ ) had a mean age of 75.6 years (range, 63-93 years) at the time of the survey, and the mean number of years since cataract surgery was 4.5 years (range, 2-8 years). YAG capsulotomies had been performed since surgery in 29 (43\%) patients in group 1 and $19(39 \%)$ in group 2. Refractive enhancement surgery had been performed following cataract surgery in five patients $(7 \%)$ in group 1 and four patients $(8 \%)$ in group 2 . These differences were not statistically significant. No patient underwent a lens exchange after the initial cataract surgery in either group.

\section{Patient-reported outcomes and satisfaction}

Overall, for patient-reported satisfaction, there were no significant differences between groups 1 and 2 or within each group between the different lenses used. In group 1, 67 of $68(97 \%)$ of patients and in group 2, 44 of $49(90 \%)$ patients were either "very satisfied" or "somewhat satisfied" 


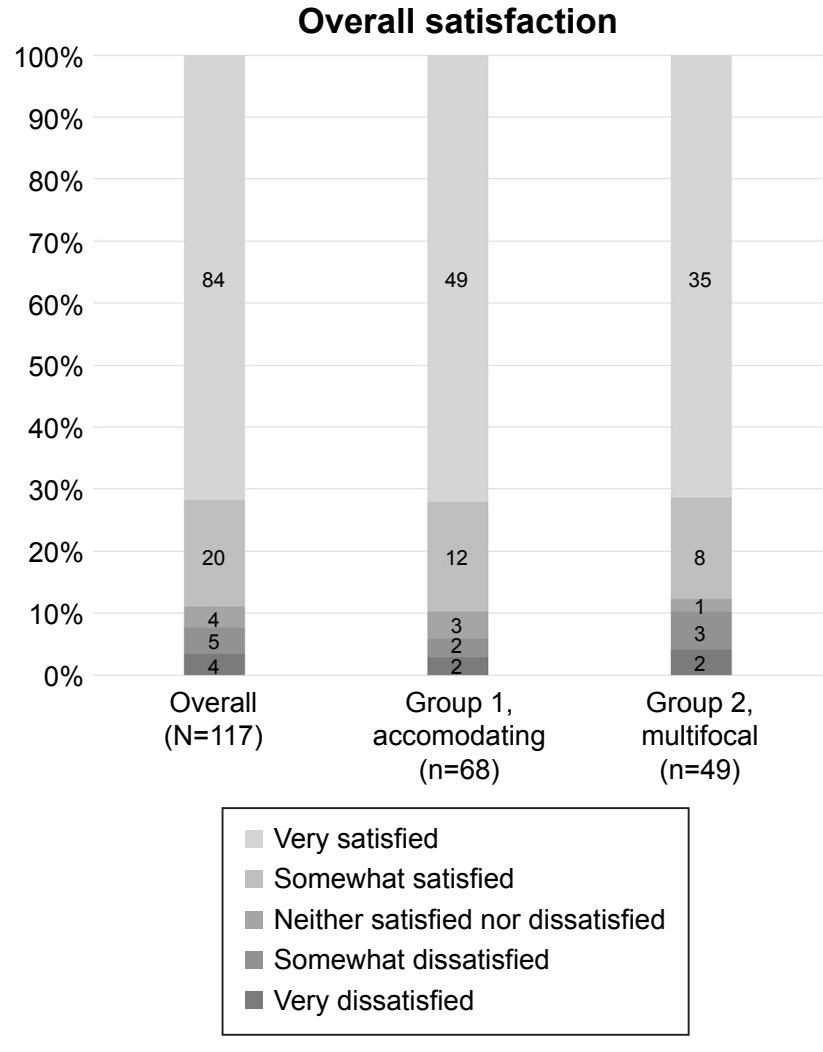

Figure I Patient satisfaction levels at least 2 years after presbyopia-correcting intraocular lens implantation.

Note: About $90 \%$ of patients in each group were "very satisfied" or "somewhat satisfied" with their vision at least 2 years after the initial surgery.

with their vision at least 2 years after the initial cataract surgery (Figure 1). Conversely, only one in eleven patients found their vision to be worse than expected postoperatively (Figure 2).

In group 1, 81\% were "very likely" to refer friends/family and $9 \%$ were "likely" to refer friends/family. In this group, $26 \%$ considered vision "much better" than expected and only $1 \%$ considered vision "much worse" than expected $(P<0.54)$. In Group 2, 73\% were "very likely" to refer friends/family and $16 \%$ were "likely" to refer friends/family. In this group, $35 \%$ considered vision "much better" than expected and only $4 \%$ considered vision "much worse" than expected. The betweengroup differences were not statistically significant.

Both the groups wanted daylight driving and reading newspaper print without glasses as their top two desired activities postoperatively; $65 \%$ of group 2 and $54 \%$ of group 1 $(P<0.67)$ wanted nighttime driving to be spectacle-free.

\section{Patient-reported dissatisfaction}

In group 1, six of 68 patients (8.8\%) considered vision worse than expected. In group 2 , six of 49 patients (12\%) considered vision worse than expected. More patients in group 2 than in

\section{Current vision vs expectations}

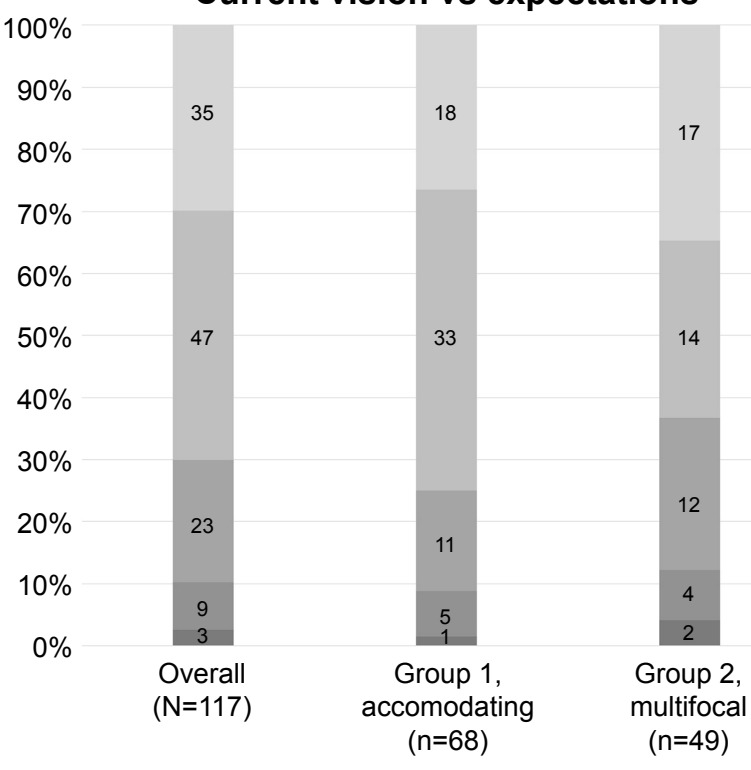

Much better than expected

Better than expected

- About the same

Worse than expected

Much worse than expected

Figure 2 Patient expectations with vision at least 2 years after presbyopia-correcting intraocular lens implantation.

Notes: The majority of patients in both groups reported current vision the same as or better than expected. Only one in eleven patients found his vision to be worse than expected.

group 1 complained of glare; more patients in group 1 than in group 2 complained of difficulty reading fine print spectaclefree. In group 1, the top two reasons for dissatisfaction were reading fine print more difficult than anticipated $(n=5)$ and the need to wear glasses more than anticipated $(n=4)$. In group 2 , the top two reasons for dissatisfaction were being bothered by glare/halo $(n=3)$ and reading fine print more difficult than anticipated $(n=3)$.

\section{Glare and halos}

More patients in group $2(56 \%)$ than group 1 (31\%) were bothered by glare and halo; this was statistically significant $(P<0.02)$. Conversely, $44 \%$ of patients in group 1 and $16 \%$ of patients in group 2 were "not at all" bothered by glare and halo $(P<.001)$. In group $1,12 \%$ of patients were "very much" or "extremely" bothered by glare and halo, whereas in group $2,36 \%$ of patients were "very much" or "extremely" bothered by glare and halo $(P<0.02)$.

\section{Spectacle need}

Patients reported generally small differences in spectacle independence between groups. For watching television, 
$76 \%$ of patients in group 1 and $73 \%$ of patients in group 2 reported they "never" wore spectacles. For driving during daylight, $70 \%$ in group 1 and $75 \%$ in group 2 reported they never wore glasses, and for driving at night, $62 \%$ in group 1 and $67 \%$ in group 2 similarly reported no need for spectacles. For near vision tasks, $54 \%$ of patients in group 1 and $63 \%$ in group 2 reported never needing spectacles to see the computer monitor. None of these differences were statistically significant. However, there were significant differences for reading newspaper-sized print, where $48 \%$ in group 1 and $63 \%$ in group 2 reported complete spectacle independence $(P<0.03)$, and for reading fine print smaller than newsprint, $22 \%$ in group 1 and $46 \%$ in group 2 reported never needing spectacles $(P<0.02)$.

When asked if the patients would choose a different lens that would increase the need for reading glasses, but reduce the glare side effect, the majority of patients in both the groups would not (group 1, 71\%; group 2, 72\%). Patients in both the groups were "somewhat bothered" by needing glasses for different activities. These differences were not statistically significant.

\section{Subgroup analyses}

As technology evolved, patients received the current design for the IOL brands at the time of implant. Subgroup analyses of the various models within each brand showed no trend toward different results for any subgroup.

\section{Discussion}

This study was designed to evaluate patient satisfaction levels more than 5 years after cataract surgery with either an accommodating or a multifocal lens implant. This is significant because the average patients undergoing cataract surgery in the US are aged 69 years, ${ }^{9}$ and the average life expectancy in the US is 79 years. ${ }^{10}$ Thus, this study evaluates patientreported outcomes and satisfaction of the "average" patients after half their remaining lifespan has passed.

In this study there were high levels of patient-reported satisfaction and a generally high level of acceptance of visual disturbances, such as halo and glare. Even with these visual disturbances, patients were generally unwilling to trade reduced visual disturbances if the tradeoff meant increased spectacle correction.

Multifocal lenses are widely thought to be the lens of choice for spectacle independence across a wide range of distances post-cataract surgery/post-refractive lens exchange surgery. ${ }^{11-13}$ However, this study suggests that patient satisfaction is similar at least 5 years after cataract surgery between multifocal and accommodating lenses. Each type of lens has been designed to perform differently, although both attempt to provide better postoperative vision across multiple range of vision than a monofocal lens.

Multifocal IOLs are known for dysphotopsia (including glare and halo) that can negatively impact the quality of life. ${ }^{14}$ Glare and halo have been found to be substantially more common in this type of lens than in standard monofocal lenses; one study cited the occurrence of glare and halo as 3.5 times more common than in monofocal lenses. ${ }^{14,15}$ The US Food and Drug Administration professional labeling of some multifocal IOLs also includes a warning about contrast sensitivity and advises patients to exercise caution when driving at night. ${ }^{16}$ Pepose et al showed that multifocal IOL implantation (unilateral or bilateral) resulted in more night driving issues and low-contrast issues. ${ }^{16}$ Advocates of this technology note that any dysphotopsia tends to diminish over time and attribute that dimunition to neuroadaptation. This study found that if neuroadaptation occurred, it had little effect on patients' ability to notice or be bothered by these dysphotopsia.

Pepose et al also showed bilateral implantation with an accommodating lens or a "mix and match" combination of an accommodating lens and a multifocal lens had statistically better visual outcomes than bilateral multifocal IOL implantation. ${ }^{16}$ Those results were only 6 months after surgery; this study's results were at least 2 years after surgery, but do reinforce the earlier bilateral same-lens findings.

Glare and halo by themselves are not an unusual phenomenon and can occur to some degree in almost any pseudophakic patient. The causes can range from minor posterior capsule opacification to minor residual refractive error to ocular surface disease. In this study, the percentage of patients affected by dysphotopsia in the accommodating lens group was similar to the percentages reported by patients receiving monofocal IOLs in other studies. ${ }^{17-19}$

In group 1, 37 of the patients received a Crystalens HD. Those implants had a $3.0 \mathrm{~mm}$ central zone with a different focal power than the lens periphery. Crystalens HD is prone to more dysphotopsia than previous generations of the lens. ${ }^{20-22}$ The newest lower add generation of accommodating lenses (Crystalens AO) has a uniform lens power across the optic, designed to reduce dysphotopsia. ${ }^{21}$ Yet within group 1 in this study, there was no difference in the incidence of complaints about glare or halos among patients receiving Crystalens HD than among patients with more recent designs.

Similarly, patients in group 2 were implanted with the AcrySof ReSTOR 3.25 or the Tecnis Multifocal 4.0D, 
depending on patient choice and lens availability. Since these patients underwent their cataract surgeries, newer iterations of multifocal lenses have been introduced in the marketplace that add between 2.5 and $2.75 \mathrm{D}$ to the "near" zone, shifting the traditional near zone to the intermediate zone. These newer lenses are sometimes referred to as "extended depth of focus." 23,24 By sacrificing uncorrected vision at the nearest working distances, these lenses also claim to reduce the amount of dysphotopsia. The author believes that this same patient questionnaire, if administered in the year 2020 to evaluate patient perceptions long-term with today's multifocal and accommodating lenses, would yield similar results between the two groups on issues such as spectacle independence for near tasks.

Cataract refractive surgeons readily agree that patients with comorbidities such as dry eye, mild maculopathy, and corneal aberrations as a result of previous refractive surgery or that occur natively may not be candidates for a multifocal lens because the visual limitations caused by these diseases may cause intolerance of a lens that also causes a loss of contrast sensitivity. Those same comorbidities have not been viewed as a contraindication for accommodating lenses.

Although this patient questionnaire did not address astigmatism, its correction has been shown to be another critical component to patient satisfaction. ${ }^{25,26}$ Toric IOLs are generally perceived by cataract surgeons as providing the most complete lens-based astigmatic correction offering both high efficacy and safety when compared to other procedures. Were this questionnaire re-administered in the year 2020, we would expect to include patients who received toric accommodating lenses and, based on the results from this patient-reported outcome survey, would predict their satisfaction level would be greater than those who received standard monofocal lenses or newer iterations of multifocal lenses.

\section{Conclusion}

Patient-reported outcomes indicate that the majority of patients who received either accommodating or multifocal IOLs remain satisfied with their lens of choice more than 5 years after the original surgery. Glare and halos remain more noticeable in patients who received multifocal lenses.

\section{Acknowledgments}

This study was supported by Bausch + Lomb. Partial results have been presented at the Royal Hawaiian Eye Meeting, 2016. Portions of this study were presented at the American Society of Cataract \& Refractive Surgeons meeting in 2015.

\section{Disclosure}

Dr Hovanesian is a consultant to Alcon, Bausch + Lomb, and Johnson \& Johnson Vision. The author reports no other conflicts of interest in this work.

\section{References}

1. Abdelghany AA, Alio JL. Surgical options for correction of refractive error following cataract surgery. Eye Vis. 2014;1:2.

2. Yıldırım Karabağ R, Günenç Ü, Aydın R, Arıkan G, Aslankara H. Visual Results Following Implantation of a Refractive Multifocal Intraocular Lens in One Eye and a Diffractive in the Contralateral Eye. Turk $J$ Ophthalmol. 2018;48(1):6-14.

3. Mcneely RN, Pazo E, Spence A, et al. Visual outcomes and patient satisfaction 3 and 12 months after implantation of a refractive rotationally asymmetric multifocal intraocular lens. J Cataract Refract Surg. 2017;43(5):633-638.

4. Chang JS, Ng JC, Lau SY. Visual outcomes and patient satisfaction after presbyopic lens exchange with a diffractive multifocal intraocular lens. J Refract Surg. 2012;28(7):468-475.

5. Chang JS, Ng JC, Chan VK, Law AK. Visual outcomes and patient satisfaction after refractive lens exchange with a single-piece diffractive multifocal intraocular lens. J Ophthalmol. 2014;2014:458296-8.

6. Braga-Mele R, Chang D, Dewey S, et al. Multifocal intraocular lenses: relative indications and contraindications for implantation. $J$ Cataract Refract Surg. 2014;40(2):313-322.

7. Gundersen KG, Makari S, Ostenstad S, Potvin R. Retreatments after multifocal intraocular lens implantation: an analysis. Clin Ophthalmol. 2016;10:365-371.

8. Shimoda T, Shimoda G, Hida WT, et al. Visual outcomes after implantation of a novel refractive toric multifocal intraocular lens. Arq Bras Oftalmol. 2014;77(2):71-75.

9. Schein OD, Cassard SD, Tielsch JM, Gower EW. Cataract surgery among Medicare beneficiaries. Ophthalmic Epidemiol. 2012;19(5):257-264.

10. Centers for Disease Control and Prevention. Life expectancy; 2017. Available from: https://www.cdc.gov/nchs/fastats/life-expectancy.htm. Accessed June 19, 2017.

11. Hawker MJ, Madge SN, Baddeley PA, Perry SR. Refractive expectations of patients having cataract surgery. J Cataract Refract Surg. 2005; 31(10): 1970-1975.

12. Pager CK. Expectations and outcomes in cataract surgery: a prospective test of 2 models of satisfaction. Arch Ophthalmol. 2004;122(12): $1788-1792$.

13. Muñoz G, Albarrán-Diego C, Ferrer-Blasco T, Sakla HF, GarcíaLázaro S. Visual function after bilateral implantation of a new zonal refractive aspheric multifocal intraocular lens. J Cataract Refract Surg. 2011;37(11):2043-2052.

14. Sheppard AL, Shah S, Bhatt U, Bhogal G, Wolffsohn JS. Visual outcomes and subjective experience after bilateral implantation of a new diffractive trifocal intraocular lens. J Cataract Refract Surg. 2013;39(3):343-349.

15. Leyland M, Zinicola E. Multifocal versus monofocal intraocular lenses in cataract surgery: a systematic review. Ophthalmology. 2003;110(9): 1789-1798.

16. Pepose JS, Qazi MA, Davies J, et al. Visual performance of patients with bilateral vs combination Crystalens, ReZoom, and ReSTOR intraocular lens implants. Am J Ophthalmol. 2007;144(3):347-357.

17. Allen R, Ho-Yen GO, Beckingsale AB, Fitzke FW, Sciscio AG, Saleh GM Post-capsulotomy dysphotopsia in monofocal versus multifocal lenses. Clin Exp Optom. 2009;92(2):104-109.

18. Wilkins MR, Allan BD, Rubin GS, et al. Randomized trial of multifocal intraocular lenses versus monovision after bilateral cataract surgery. Ophthalmology. 2013;120(12):2449-2455.

19. Martínez Palmer A, Gómez Faiña P, España Albelda A, Comas Serrano M, Nahra Saad D, Castilla Céspedes M. Visual function with bilateral implantation of monofocal and multifocal intraocular lenses: a prospective, randomized, controlled clinical trial. J Refract Surg. 2008;24(3):257-264. 
20. Devgan U, Lindstrom RL, Singer JA, Whitman J. First Impressions of the Crystalens HD. Cataract \& Refractive Surgery Today. Bryn Mawr, PA: BMC Publications; 2008.

21. Kezirian GM, Chu YR, Feinerman G. Crystalens AO: Surgical Experience. Cataract \& Refractive Surgery Today. Bryn Mawr, PA: BMC Publications; 2010.

22. Slade SG. Strategies for Success with Five Refractive IOLs. Cataract \& Refractive Surgery Today. Bryn Mawr, PA: BMC Publications; 2009.

23. Calogero D. New Categories of IOLs for Improved Near and Intermediate Performance. Washington, DC: United States Food and Drug Administration; 2014
24. Gallego AA, Bará S, Jaroszewicz Z, Kolodziejczyk A. Visual Strehl performance of IOL designs with extended depth of focus. Optom Vis Sci. 2012;89(12):1702-1707.

25. Gyöngyössy B, Jirak P, Schönherr U. Rotational stability and patient satisfaction after implantation of a new toric IOL. Eur J Ophthalmol. 2016;26(4):321-327.

26. Farooqui JH, Koul A, Dutta R, Shroff NM. Management of moderate and severe corneal astigmatism with AcrySof ${ }^{\mathbb{B}}$ toric intraocular lens implantation - Our experience. Saudi J Ophthalmol. 2015;29(4): 264-269. 


\section{Supplementary material}

1) Overall, how satisfied are you with your vision after your surgery?

(5 Pt Scale): Very satisfied, Somewhat satisfied, Neither satisfied nor dissatisfied, Somewhat dissatisfied or Very dissatisfied

2) How likely would you be to refer a friend or family member for the same surgery with the same implant?

(5 Pt Scale): Very likely, Somewhat likely, Neither likely nor unlikely, Somewhat unlikely or Very unlikely

3) Compared to what you expected, would you say your vision now is...

(5 Pt Scale): Much better than expected, Better than expected, About the same as expected, Worse than expected, Much worse than expected

[AMONG THOSE WHO STATED WORSE THAN EXPECTED OR MUCH WORSE THAN EXPECTED]

3-1) In what way(s) is your vision worse than expected? (select all that apply)

- Even with glasses, everything is not as clear as I expected.

- I have to wear glasses more than I expected.

- Other problems not related to my cataract surgery have made my vision worse than expected.

- I am bothered by glare and haloes around bright lights.

- Reading fine print is more difficult than I expected.

- Driving after dark is more difficult than I expected.

- Driving during the day is more difficult than I expected.

4) With or without glasses, how much do you notice glare or haloes around lights in dim light situations?

(5 Pt Scale): Not at all, Very little, Somewhat, Very much, Extremely

[AMONG THOSE WHO STATED VERY LITTLE TO EXTREMELY]

4-1) How bothered are you by these glare/halo symptoms?

(5 Pt Scale): Not at all, Very little, Somewhat, Very much, Extremely

4-2) If at the time of surgery you could have chosen a different implant that would cause less glare or haloes, would you have made that choice?

(3 Pt Scale) Yes, No, Maybe

4-3) Would you have chosen that different implant with less glare and haloes, even if it required you to wear glasses more for reading and other activities?

(3 Pt Scale) Yes, No, Maybe

4-4) Can you explain your answers to these last two questions?

(Text Response)

5) For which activities is it most desirable for you to see without corrective lenses (select all that apply)?

- Driving during the day

- Driving at night

- Seeing the computer monitor

- Using your mobile phone

- Watching TV

- Sports/hobbies

- Reading newspaper size print

- Reading fine print smaller than newsprint (medicine bottles, for example)

6) For each of the activities below, tell me how often you need to wear glasses?

Driving during the day

(5 Pt Scale) I don't do this activity, Never, Occasionally, Frequently, All the time

Driving at night

(5 Pt Scale) I don't do this activity, Never, Occasionally, Frequently, All the time

Seeing the computer monitor

(5 Pt Scale) I don't do this activity, Never, Occasionally, Frequently, All the time

Using your mobile phone

(5 Pt Scale) I don't do this activity, Never, Occasionally, Frequently, All the time Watching TV

(5 Pt Scale) I don't do this activity, Never, Occasionally, Frequently, All the time Sports/hobbies

(5 Pt Scale) I don't do this activity, Never, Occasionally, Frequently, All the time Reading newspaper size print

(5 Pt Scale) I don't do this activity, Never, Occasionally, Frequently, All the time Reading fine print smaller than newsprint (medicine bottles, for example)

(5 Pt Scale) I don't do this activity, Never, Occasionally, Frequently, All the time

Figure SI (Continued) 
[AMONG THOSE WHO CHOSE SPORTS/HOBBIES OCCASIONALLY, FREQUENTLY OR ALL THE TIME]

6-1) What sports/hobbies require the use of eyeglasses the most? (select all that apply)

- Tennis or racquet sports

- Golf

- Playing cards/games

- Other outdoor activities (text box)

- Other indoor activities (text box)

[AMONG THOSE WHO STATED NEEDING TO WEAR GLASSES OCCASIONALLY, FREQUENTLY OR ALL THE TIME]

6-2) How bothered are you by needing to wear glasses for some activities?

(5 Pt Scale) Not at all, Very little, Somewhat, Very much, Extremely

7) Other than the answers you gave above, what, if anything, do you like about having had your surgery?

(Text Response)

8) Other than the answers you gave above, what, if anything, do you dislike about having had your surgery?

(Text Response)

Figure SI Two-year postsurgery satisfaction and function questionnaire.

\section{Publish your work in this journal}

Clinical Ophthalmology is an international, peer-reviewed journal covering all subspecialties within ophthalmology. Key topics include: Optometry; Visual science; Pharmacology and drug therapy in eye diseases; Basic Sciences; Primary and Secondary eye care; Patient Safety and Quality of Care Improvements. This journal is indexed on
PubMed Central and CAS, and is the official journal of The Society of Clinical Ophthalmology (SCO). The manuscript management system is completely online and includes a very quick and fair peer-review system, which is all easy to use. Visit http://www.dovepress.com/ testimonials.php to read real quotes from published authors. 